\title{
Correction to: Efficient Certificateless Signcryption Scheme for Wireless Sensor Networks in Ubiquitous Healthcare Systems
}

\author{
Philemon Nthenge Kasyoka ${ }^{1,2}$ (D) Michael Kimwele ${ }^{2} \cdot$ Shem Angolo Mbandu $^{3}$
}

Published online: 12 March 2021

(C) Springer Science+Business Media, LLC, part of Springer Nature 2021

\section{Correction to: Wireless Personal Communications https://doi.org/10.1007/s11277-021-08183-y}

There was a spelling error in the second author's name in the initial online publication. The original article has been corrected.

Publisher's Note Springer Nature remains neutral with regard to jurisdictional claims in published maps and institutional affiliations.

The original article can be found online at https://doi.org/10.1007/s11277-021-08183-y.

Philemon Nthenge Kasyoka

pkasyoka@gmail.com

1 School of Computing and Information Technology, Jomo Kenyatta University of Agriculture and Technology, P.O. Box 62000-00200 Nairobi, Kenya

2 School of Information and Communication Technology, South Eastern Kenya University, P.O. Box 170-90200 Kitui, Kenya

3 School of Computing and Mathematics, Co-operative University of Kenya, P.O. Box 24814-00502 Karen, Nairobi, Kenya 